\title{
Identification of infrasonic and seismic components of tremors in single-station records: application to the 2013 and 2018 events at loto Island, Japan
}

\author{
Aika K. Kurokawa ${ }^{1 *}$ (1) and Mie Ichihara ${ }^{2}$
}

\begin{abstract}
Infrasonic stations are sparse at many volcanoes, especially those on remote islands and those with less frequent eruptions. When only a single infrasound station is available, the seismic-infrasonic cross-correlation method has been used to extract infrasound from wind noise. However, it does not work with intense seismicity and sometimes mistakes ground-to-atmosphere signals as infrasound. This paper proposes a complementary method to identify the seismic component and the infrasonic component using a single microphone and a seismometer. We applied the method to estimate the surface activity on loto Island. We focused on volcanic tremors during the phreatic eruption on April 11,2013, and during an unconfirmed event on September 12, 2018. We used the spectral amplitude ratios of the vertical ground motion to the pressure oscillation and compared those for the tremors with those for known signals generated by volcano-tectonic earthquakes and airplanes flying over the station. We were able to identify the infrasound component in the part of the seismic tremor with the 2013 eruption. On the other hand, the tremor with the unconfirmed 2018 event was accompanied by no apparent infrasound. We interpreted the results that the infrasound with the 2013 event was excited by the vent opening or the ejection of ballistic rocks, and the 2018 event was not an explosive eruption either on the ground or in the shallow water. If there was any gas (and ash) emission, it might have occurred gently undersea. As the method uses the relative values of on-site records instead of the absolute values, it is available even if the instrument sensitivity and the station site effects are poorly calibrated.
\end{abstract}

Keywords: Volcanic tremor, Infrasound, Vertical ground motion, Spectral ratio, loto Island

\section{Introduction}

Eruption in isolated volcanic islands are becoming the focus of attention for their significant growth, as in the case of Nishinoshima (Maeno et al. 2016; Kaneko et al. 2019), and for the hazardous nature, as in Anak Krakatau (Williams et al. 2019; Perttu et al. 2020) and White Island more recently (Dempsey et al. 2020). The existence of abundant water tends to cause hazardous eruptions like phreatomagmatic and phreatic explosions (Mastin

\footnotetext{
*Correspondence: kurokawa@bosai.go.jp

${ }^{1}$ National Research Institute for Earth Science and Disaster Resilience, 3-1

Tennodai, Tsukuba, Ibaraki 305-0006, Japan

Full list of author information is available at the end of the article
}

and Witter 2000; Stix and Moor 2018). It is often the case in isolated islands, the occurrences, the times, and the sequences of eruptions are not identified due to the lack of observations. The detection is particularly hard for small but frequent eruptions because signals are not strong enough to reach the global monitoring network.

Infrasound is generated by activity such as opening vent and emission of volcanic gas and rocks so that it is useful to distinguish the volcano's surface activity from underground processes (e.g., Ripepe et al. 2018). When infrasound data during an eruption is available only from a single station, it is difficult to distinguish the eruption signals from wind noise. To detect infrasound signals, 
Ichihara et al. (2012) proposed a cross-correlation analysis between the pressure oscillation and ground motion signals, which has been applied successfully with some improvements (e.g., Cannata et al. 2013; Matoza and Fee 2014; Nishida and Ichihara 2015; Ichihara 2016; Yukutake et al. 2018). McKee et al. (2018) extended the method by incorporating the phase shift and the seismic particle motion to estimate the infrasound back azimuth. However, the method is not applicable when the volcano is seismically very active, and the seismic signal dominates infrasound signal in the seismometer record. Moreover, if the ground velocity associated with the seismic wave is significantly large, it generates pressure perturbation that is noticeable in the infrasound data (Kim et al. 2004; Watada et al. 2006). Such a ground-to-atmosphere signal can be mistaken as an infrasound signal when only a single infrasound station exists.

Ioto Island is an isolated volcanic island of which seismicity is regularly intense (Ueda et al. 2018). At Ioto Island, phreatic eruptions frequently occur due to the high geothermal activity (Notsu et al. 2005), and the volcanic activity is pronounced not only on the ground, but also undersea detected by remote hydrophones (Matsumoto et al. 2019). In this situation where the volcanic activity is very high throughout the island, there is a need to monitor eruptions and its temporal changes.

This study aims to identify volcanic infrasound using a single pair of seismometer and microphone at Ioto Island. By comparing the data of the tremors associated with the 2013 eruption and the unconfirmed 2018 event with those of volcano-tectonic earthquakes and humanmade infrasound, we distinguish tremors including infrasound and purely seismic tremors.

\section{Volcanic activities at loto Island in 2013 and 2018}

Ioto Island (Iwo-jima) is one of the most active isolated volcanic islands in Japan, located approximately 1200 $\mathrm{km}$ south of Tokyo and belongs to the Izu-Bonin-Mariana island arc. The island, about $8 \mathrm{~km} \times 4 \mathrm{~km}$ in size with the highest elevation of $170 \mathrm{~m}$, is just the summit part of a stratovolcano rising about $2000 \mathrm{~m}$ from the sea floor. Eruptions sometimes occur under the sea and are detected by remote hydrophones (Matsumoto et al. 2019). The seismic activity is intense and a large-scale uplift has continued for centuries (Kaizuka et al. 1985; Ueda et al. 2018). Although minor phreatic explosions seem to occur frequently at various points in the island (Corwin and Foster 1959; Notsu et al. 2005; Ueda et al. 2018), most of them have not been confirmed in terms of their occurrences, times, and source vents.

An eruption occurred at about 16:00 JST (all times hereafter are in JST, which is UTC+0900) on April 11, 2013, has been observed from the ground and the sky and recorded by time-identified photographs (Japan Meteorological Agency 2013). It occurred at Million dollar hole (Fig. 1) with dark smoke of $400 \mathrm{~m}$ height and large ballistic rocks while the seismic activity and crustal movement were less intensive. It accompanied a volcanic tremor lasting about 9 min from 15:59 on April 11.

Another activity seems to have occurred in shallow water near the Okinahama coast (Fig. 1) on September 12,2018 , though the only evidence is water spouts with heights of 5-10 m observed at around 11:00 on the day (Japan Meteorological Agency 2018). It was preceded by predominant uplift and high-frequency seismicity for a few weeks. Data from local seismometers and remote hydrophones during the period indicate that frequent undersea eruptions associated with volcano-tectonic earthquakes occurred (Matsumoto et al. 2019). From September 12 to 13, the number of longperiod events and volcanic tremors increased while that of volcano-tectonic earthquakes decreased (Japan Meteorological Agency 2018). Then, the volcanic activity gradually declined. We investigate the 2018 activity in comparison with the confirmed case of the 2013 eruption.

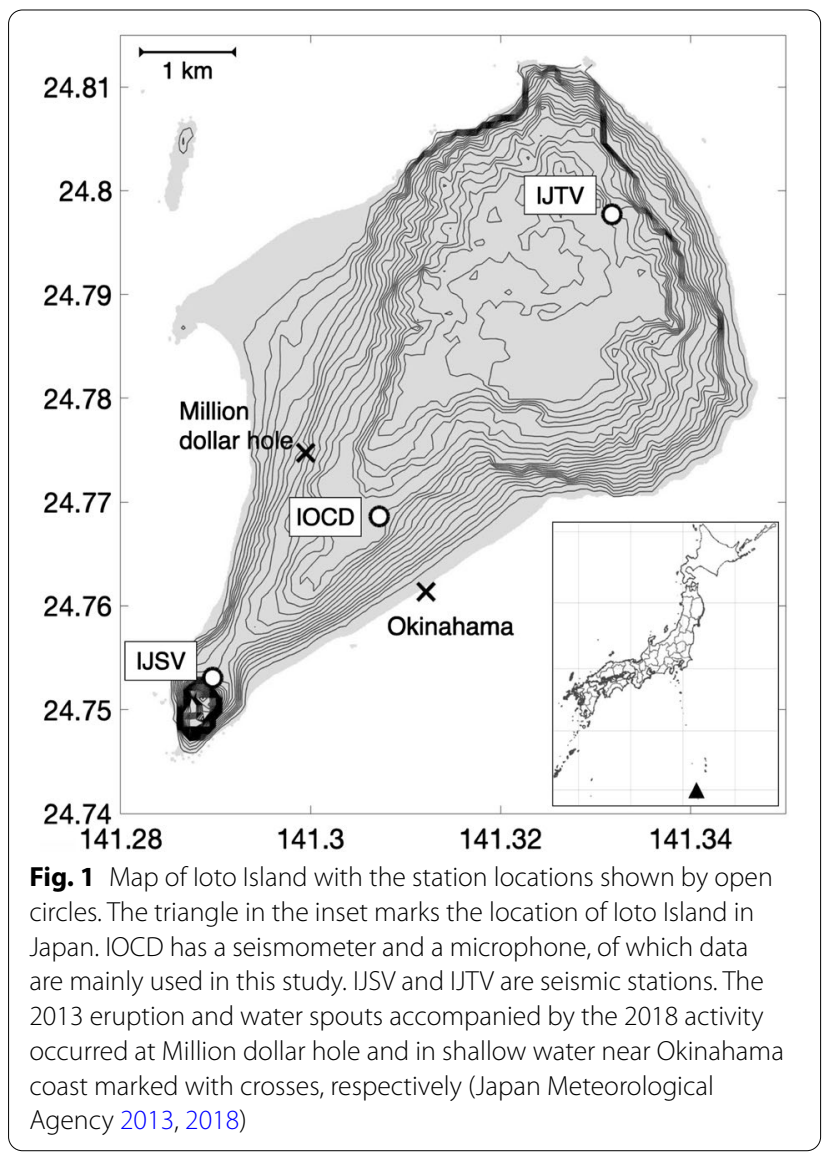




\section{Data and methods \\ Data}

We used the records at the three seismic stations in Ioto Island (Fig. 1). IOCD station of the Japan Meteorological Agency (JMA) is equipped with a velocity seismometer (L-4C, $1 \mathrm{~Hz}$, Sercel Inc.) and an infrasonic microphone (TYPE7144, > $0.1 \mathrm{~Hz}$, Aco Co., Ltd.) having a horizontal separation of $7.6 \mathrm{~m}$ and a vertical difference of 1.5 m. IJSV and IJTV stations operated by the National Research Institute for Earth Science and Disaster Resilience (NIED) have velocity seismometers (J21-3D, $1 \mathrm{~Hz}$, Mitsutoyo Corporation). The sampling frequency of all the instruments is $100 \mathrm{~Hz}$. Note that the IOCD is the only infrasonic station in Ioto Island and the nearest seismic station to the vent of 2013 eruption and the location where the water spouts were observed in the 2018 activity. The distances of IOCD to these possible sources are 1.03 and $0.94 \mathrm{~km}$, respectively.

This study focuses on two tremor events (Fig. 2); TR1 on April 11, 2013, and TR2 on September 12, 2018 (TR2 included the three sequences). TR1 coincided with the 2013 eruption (Japan Meteorological Agency 2013). On the other hand, the volcanic activity associated with TR2 is unknown, though it is the most prominent tremors during the 2018 activity (Japan Meteorological Agency 2018). We expect to determine whether TR2 accompanied infrasound or not by the combined analyses of the data from the seismometer and the microphone at IOCD.

Figure 2 shows the wave traces and the spectrograms of the whole analyzed periods for TR1 and TR2. In both TR1 and TR2, the seismic velocity amplitude is the largest at IOCD and the smallest at IJTV. The relation is consistent with the relative distances between the stations and the active areas as in Fig. 1. Although the seismic siteeffects should be considered, strictly speaking, it implies the amplitude attenuation with distance from the source. The spectrograms indicate that the dominant frequencies of TR1 and TR2 range in 1-10 and 1-5 Hz, respectively. TR1 is overlapped by an airplane noise, which has a harmonic feature with dominant frequencies about 18 and $36 \mathrm{~Hz}$ (Fig. 2c).

\section{Cross-correlation analysis}

We performed a cross-correlation analysis between the vertical ground velocity and the microphone data at IOCD. The method distinguishes infrasonic signals from wind noise, and helps detect eruption events in the situation where only one microphone is available (Ichihara et al. 2012). With the distance between the seismometer and the microphone, $d$, of $7.7 \mathrm{~m}$, the range of frequency, $f$, should satisfy the relation: $v / 3<f \cdot d \leq \alpha(v$ is the wind velocity, and $\alpha$ is the sound velocity), which guarantees that $d$ is smaller than the infrasound wave lengths and larger than correlation lengths of wind noise (Shields 2005). We assumed that $\alpha$ is $340 \mathrm{~m} / \mathrm{s}$. We also considered that $v$ is smaller than the maximum wind speed of $11.8 \mathrm{~m} / \mathrm{s}$ observed at Chichijima Island about $280 \mathrm{~km}$ to the north of Ioto Island in April 2013 and September 2018. Then, the relation is rewritten as $0.5<f \leq$ 44.2 Hz. Therefore, we used the frequency band of $1-10$ $\mathrm{Hz}$. The cross-correlation coefficient $(\mathrm{CC})$ was calculated for the delay time of the vertical ground velocity to the
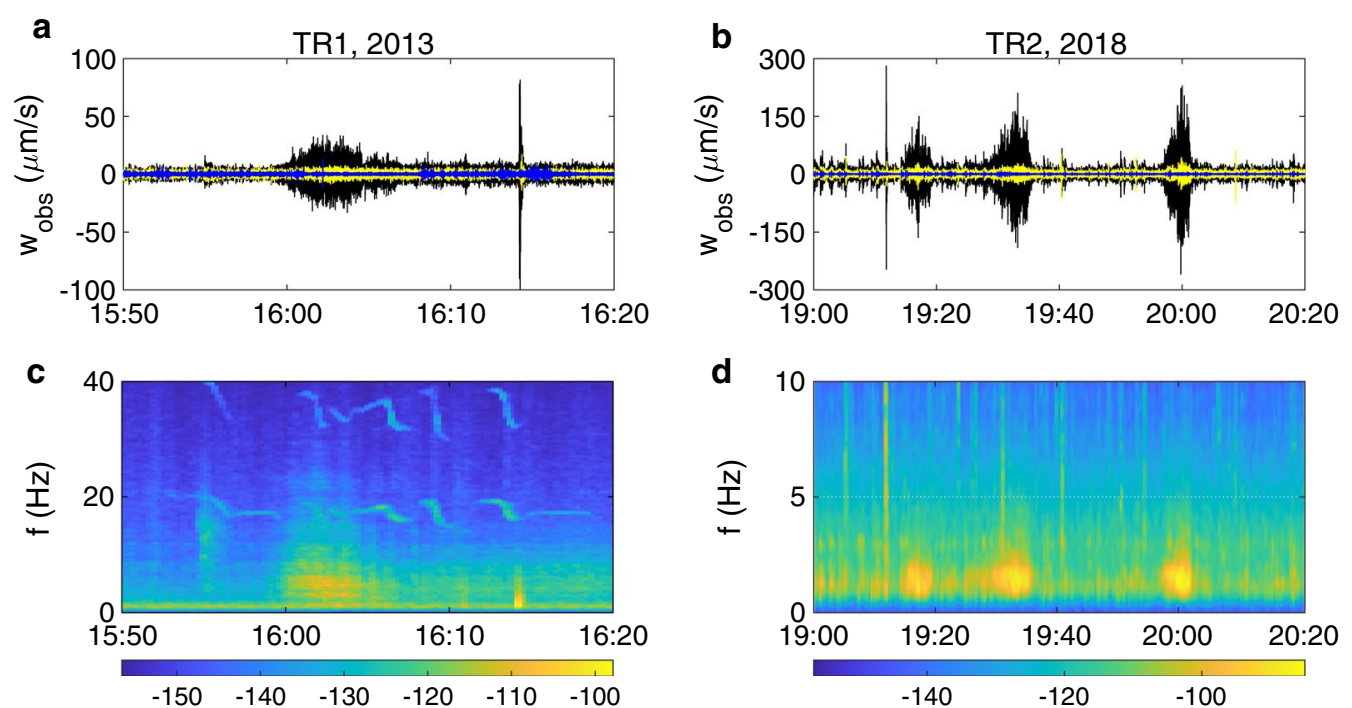

Fig. 2 Vertical ground velocity of TR1 on April 11, 2013, and TR2 on September 12, 2018. a, b The raw records at IOCD (black), IJSV (yellow), and IJTV (blue). c, d The spectrograms for the data at IOCD. The color bars indicate the power in $\mathrm{dB}=10 \log _{10}\left(\mathrm{PSD} / \mathrm{PSD}_{\text {ref }}\right)$ with PSD ref $=1\left(\mathrm{~m} \mathrm{~s}^{-1}\right)^{2} / \mathrm{Hz}$ 
microphone data from -0.5 to $0.5 \mathrm{~s}$ by use of a 5 -s time window sliding every $1 \mathrm{~s}$.

\section{Seismic and infrasonic spectral ratio}

Seismic waves propagating in the ground and infrasound waves propagating in the atmosphere individually generate both of ground motion and pressure oscillation. Therefore, it is not apparent whether an oscillation recorded by a single sensor (either a seismometer or a microphone) is a seismic or infrasonic wave. The basic theory for the acoustic coupling between the ground and the atmosphere is described in Appendixes A and B. We here only present the essential point.

When infrasound propagates along the ground surface, the vertical ground velocity, $w_{p}(f)$, induced by the infrasonic pressure wave, $p_{\text {in }}(f)$, is given in the frequency domain by

$$
w_{p}(f)=\frac{\alpha}{2\left(\lambda^{\prime}+\mu^{\prime}\right)} \frac{\lambda^{\prime}+2 \mu^{\prime}}{\mu^{\prime}} p_{\text {in }}(f) e^{-i \pi / 2},
$$

where $\left(\lambda^{\prime}, \mu^{\prime}\right)$ are Lamé's constants for the ground (BenMenahem and Singh 1981). The effective values of Lamé's constants vary with stations and depend on frequency because they are influenced by the shallow structure of the ground and topography (Langston 2004; Nishida and Ichihara 2015). Empirically, $\left|w_{p}(f) / p_{\text {in }}(f)\right|$ ranges $0.1-10$ $\mu \mathrm{m} \mathrm{s}^{-1} / \mathrm{Pa}$ (e.g., Langston 2004; Matoza and Fee 2014; Nishida and Ichihara 2015; Ichihara 2016).

On the other hand, when the vertical ground velocity due to the propagating seismic wave, $w_{\text {in }}(f)$, induces local air pressure perturbations, $p_{w}(f)$, in a homogeneous fluid medium assuming that the time scale of the vertical motion is short compared with the acoustic cut-off period in the atmosphere, the relation is formulated as

$$
p_{w}(f)=\rho \alpha w_{\text {in }}(f),
$$

where $\rho$ is the density of air (Cook 1971; Donn and Posmentier 1964; Kim et al. 2004). There exist records of ground-to-atmosphere signals excited by large earthquakes, which have a good agreement with the theory (Kim et al. 2004; Watada et al. 2006). In these cases, $\left|w_{\text {in }}(f) / p_{w}(f)\right|$ is as large as $3000 \mu \mathrm{m} \mathrm{s} / \mathrm{Pa}$. Because the spectral amplitude ratio of seismometer data to microphone data is significantly different depending on whether the wave is seismic or infrasonic, we use it to distinguish the waves. For convenience, the observed spectral amplitude ratio will be referred to as $(w / p)_{\text {obss }}$.

We calculated $(w / p)_{\text {obs }}$ for each of TR1 and TR2 in the following steps. (1) Power spectral densities (PSDs) of the seismic data (the vertical component) and infrasonic record were individually calculated in a 10-s window sliding with 5-s overlapping for the periods shown in Fig. 2. (2) The wind is the most critical noise in the infrasound record, which has significant power in low frequencies below $1 \mathrm{~Hz}$ (Fee and Garces 2007). Therefore, we focused on the frequency range above $1 \mathrm{~Hz}$ in searching for volcanic signals. For each time window, we calculated the powers of the infrasound data in high- and low- frequency bands, $E_{\mathrm{h}}=\int_{1}^{10} \operatorname{PSD}(\mathrm{f}) \mathrm{df}$ and $E_{\mathrm{l}}=\int_{0.5}^{1} \mathrm{PSD}(\mathrm{f}) \mathrm{df}$, respectively. If $\sqrt{E_{\mathrm{h}}}>3 \sqrt{E_{\mathrm{l}}}$, we employed the time window. (3) For each of TR1 and TR2, we averaged the PSDs over the time windows selected in (2) to obtain the mean PSDs, $P_{W}(f)$ and $P_{P}(f)$, for the seismic and infrasonic data, respectively. Then, we obtained the spectral amplitude ratio, $(w / p)_{\text {obs }}$ $=\sqrt{P_{W}(f) / P_{P}(f)}$. (4) We also evaluated mean PSDs for the background noise spectra, $P_{W}^{b}(f)$ and $P_{P}^{b}(f)$, for seismic and infrasonic data, respectively. We searched the background time windows from 14:00 to 17:00 of April 11, 2013, for TR1 and from 0:00 to 24:00 of September 8,2018 , for TR2. It would be better to use time windows as close as possible to the occurrence time of the target signal to obtain a reliable background level. However, because of the intense volcanic seismicity during the 2018 activity, it was hard to extract adequate background data near the signal. Therefore, we used the time windows before the days of the intense activity. When the infrasonic PSDs above $1 \mathrm{~Hz}$ are smaller than $10^{-3} \mathrm{~Pa}^{2} / \mathrm{Hz}$ and the seismic PSDs are below $\left.5(\mu \mathrm{m} \mathrm{s})^{-1}\right)^{2} / \mathrm{Hz}$ in a time window, we regarded it as a background noise window. We took 100 time windows for each of TR1 and TR2, and averaged the PSDs to obtain $P_{W}^{b}(f)$ and $P_{P}^{b}(f)$. (5) The mean PSDs for the signals $\left(P_{W}(f)\right.$ and $P_{P}(f)$ obtained in (3)) and those for background $\left(P_{W}^{b}(f)\right.$ and $P_{P}^{b}(f)$ evaluated in (4)) were compared. The meaningful frequency bands were defined by the following condition:

$$
\frac{P_{W}(f)-a_{w} P_{W}^{b}(f)}{a_{w} P_{W}^{b}(f)}>10, \frac{P_{P}(f)-a_{p} P_{P}^{b}(f)}{a_{p} P_{P}^{b}(f)}>10 .
$$

The background noise levels were adjusted by $a_{w}$ and $a_{p}$ so that the mean PSDs for the signal and the noise were equal at $0.5 \mathrm{~Hz}$. Wind noise power generally increases in the lower frequency. The frequency of $0.5 \mathrm{~Hz}$ is below the signal's dominant frequency range and above the sensor's low-frequency limit. Namely, $a_{w}=P_{W}(0.5) / P_{W}^{b}(0.5)$, and $a_{p}=P_{P}(0.5) / P_{P}^{b}(0.5)$. The shifting was applied to remove the effect of temporal change in wind noise. The spectral characteristics of the tremors and the background noises obtained by the method are compared in Fig. 3.

For reference, we evaluated $(w / p)_{\text {obs }}$ for known infrasonic and seismic signals, which are airplane sound propagating in the atmosphere $(\mathrm{PN})$ and seismic waves generated by tectonic earthquakes (EQ). The method was 

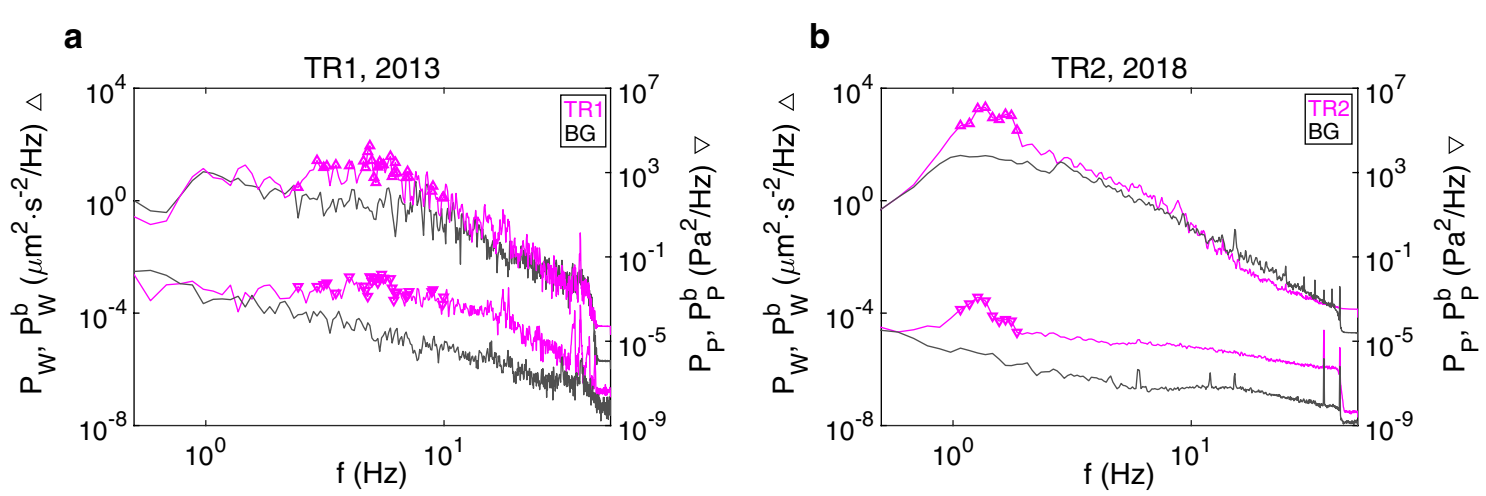

C

d
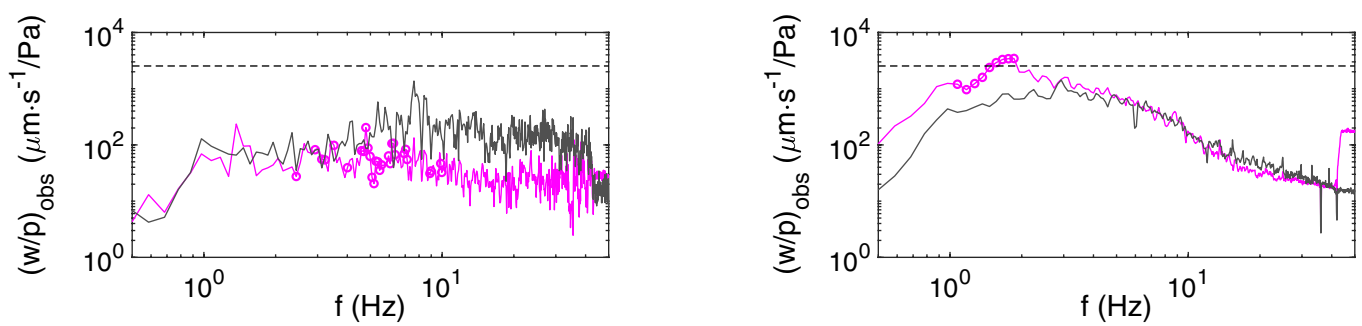

Fig. 3 Power spectral features of tremors (magenta) and background noise (black). The symbols show the values of the meaningful frequency bands selected by step (5) of the text. $\mathbf{a}, \mathbf{b}$ The upper magenta line with the upward triangles is $P_{W}$, and the associated black line is $P_{W}^{b}$, on the left axis. The lower magenta line with inverted triangles is $P_{P}$, and the associated black line is $P_{P}^{b}$ on the right axis. $\mathbf{c}$, $\mathbf{d}$ The spectral amplitude ratio between seismic record and infrasonic record, $(W / P)_{\text {obs, }}$ as a function of frequency. The horizontal dashed line indicates the theoretical value for the ground-to-atmosphere wave calculated by Eq. (2) with $\alpha=340 \mathrm{~m} / \mathrm{s}$ and $\rho=1.16 \mathrm{~kg} / \mathrm{m}^{3}$

similar to the above. For PN, we analyzed the data from 16:00 to 17:00 of April 11, 2013 and from 10:00 to 11:00 of September 12, 2018, in which we found clear airplane signals in the spectrograms. As PN signals had powers in high frequency, we changed the frequency range in step (1) to $10-40 \mathrm{~Hz}$, and the threshold of Eq. (3) to 30 in step (5). In step (2), 6 and 54 time windows met the requirement in 2013 and 2018 data, respectively. As regards EQ, we used 51 and 118 tectonic earthquakes that occurred in Ioto Island in March-April 2013 and September 2018, respectively. The timetables are shown in Additional file 1 referring to the NIED catalog. Because many earthquakes occurred in Ioto Island, signals that had good cross-correlation between the seismometer and the microphone (the CC larger than 0.6) and peak seismic amplitudes larger than $50 \mu \mathrm{m} / \mathrm{s}$ at IOCD were selected. Twenty-second records from $10 \mathrm{~s}$ before the peaks were used for calculating $P_{W}(f)$ and $P_{P}(f)$. Then, we performed step (5) to select the meaningful frequency band.

\section{Results}

The seismic and infrasonic records and the seismic-toinfrasonic CCs in the analyzed periods for TR1 and TR2 are shown in Fig. 4. Figure 5 shows results of the same analysis for the reference signals (PN and EQ). If both of the seismometer and the microphone record infrasound propagating along the ground surface, the $\mathrm{CC}$ would have a positive peak near $\tau=1 /\left(4 f_{0}\right)$, a negative peak near $\tau=-1 /\left(4 f_{0}\right)$, and a node at $\tau=0$ (Ichihara et al. 2012; Yukutake et al. 2018). We observe some change in the pattern for a few minutes from 16:00 in TR1 (Fig. 4c). However, its maximum $\mathrm{CC}$ value is not so high as that for PN (e.g., from 10:15 to 10:17 in Fig. 5c), which is close to 1 . The low CC value of TR1 suggests that the major contribution to the signal recorded by the seismometer is not infrasonic origin but seismic waves. Nevertheless, the subtle pattern change may be due to the coexistence of infrasound with the seismic tremor of TR1. On the other hand, CCs of TR2 and EQ share a feature with a positive peak around $\tau=0$ and a negative peak in $\tau>0$ as shown in Figs. $4 \mathrm{~d}$ and $5 \mathrm{~d}$. It suggests a seismic origin for TR2 signal in both seismic and infrasonic data.

Figure 6 compares the mean power spectra and $(w / p)_{\text {obs }}$ of TR1 and TR2 against PN and EQ. Figure 6c shows that $(w / p)_{\text {obs }}$ of TR1 is closer to that of PN than $\mathrm{EQ}$. The infrasonic amplitude is too large to be generated by the observed ground velocity. On the other hand, both powers of the seismic and infrasonic data during TR2 are comparable to the ground-to-atmosphere signal of EQ (Figs. $4 \mathrm{~b}, 5 \mathrm{~b}$, and $6 \mathrm{~b}$ ). These results support the inference from CC that a pressure wave accompanied TR1 but not TR2. Although the existence of infrasound for TR2 

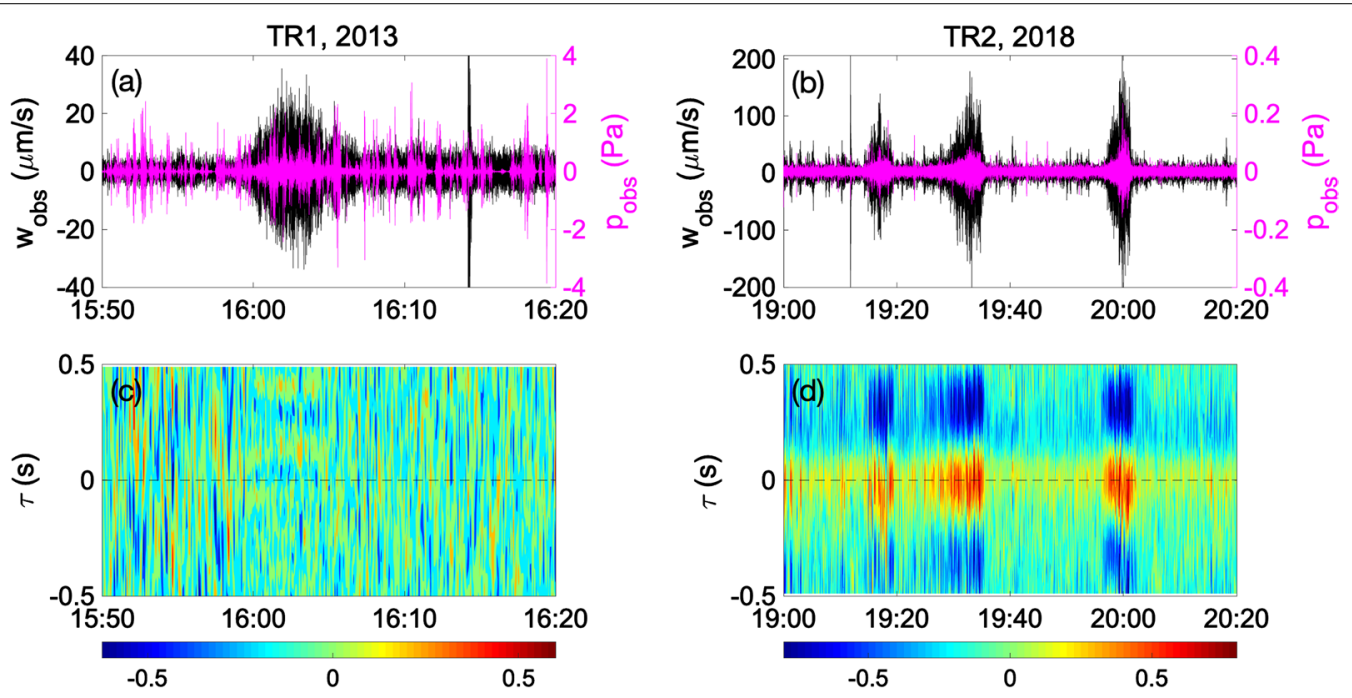

Fig. 4 a, b TR1 and TR2 waveforms recorded at IOCD. The black shows the vertical component of the seismometer, and the magenta shows the microphone record. The data were filtered within the frequency band of $1-10 \mathrm{~Hz}$. $\mathbf{c}$, $\mathbf{d}$ The cross-correlation of the seismic and infrasonic data in $\mathbf{a}, \mathbf{b}$ in a 5 -s time window sliding every $1 \mathrm{~s}$. The vertical axis, $\tau$, is the time delay of the seismic to infrasonic data
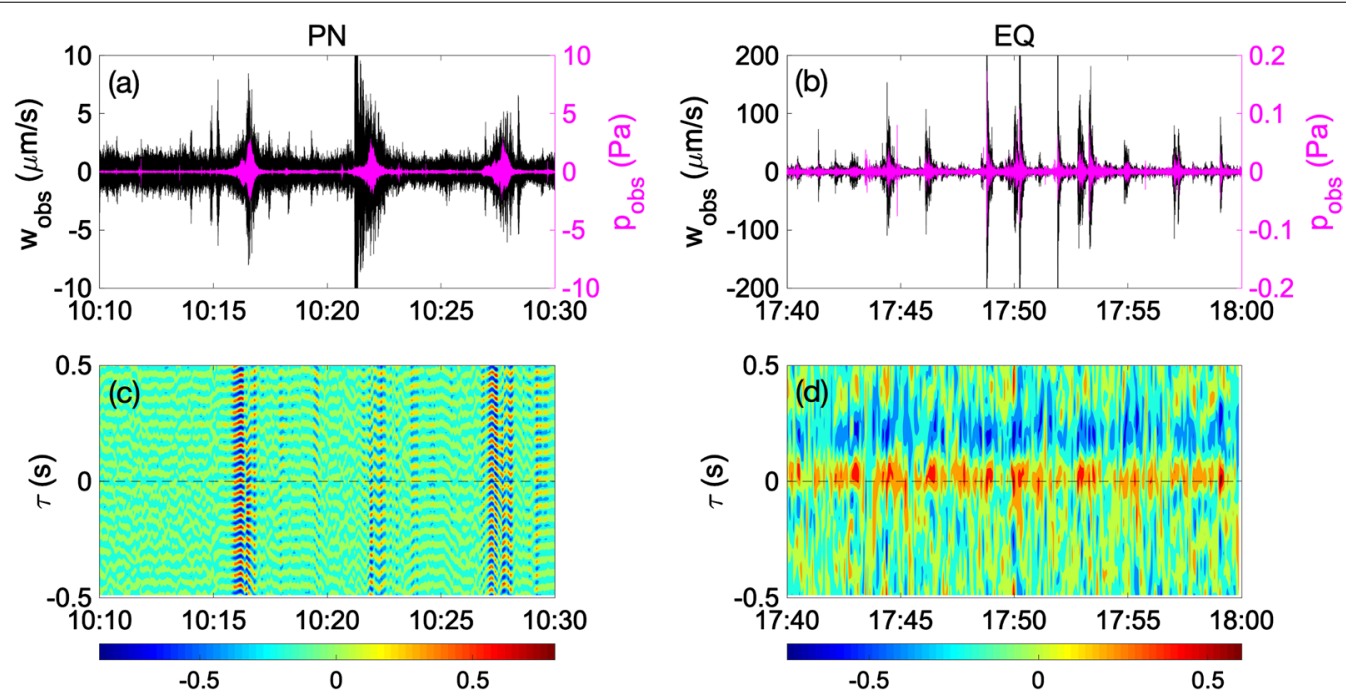

Fig. $\mathbf{5}$ a, b PN and EQ waveforms recorded at IOCD on September 12 and 18, 2018, respectively. The black shows the vertical component of the seismometer, and the magenta shows the microphone record. PN and EQ data are filtered within the frequency band of 10-30 Hzand 1-10 Hz, respectively. $\mathbf{c}, \mathbf{d}$ The cross-correlation of the seismic and infrasonic data in $\mathbf{a}, \mathbf{b}$ in a 5 -s time window sliding every $1 \mathrm{~s}$. The vertical axis, $\boldsymbol{\tau}$, is the time delay of the seismic to infrasonic data

cannot be completely ruled out, it would have been so weak to be obscured by the observed noise in the infrasound data $(<0.1 \mathrm{~Pa})$, if it happened.

\section{Discussion}

The values of $(w / p)$ obs

The spectral ratios of seismic data to infrasonic data, $(w / p)_{\text {obs }}$, were calculated to discuss the volcanic activities with TR1 and TR2, as presented in Fig. 6c, d. Here, we consider if the values of $(w / p)_{\text {obs }}$ are reasonable, focusing on the reference signals of EQ and PN. EQ that is seismic wave has $(w / p)_{\text {obs }}$ in agreement with the theoretical value of ground-to-atmosphere signals (Kim et al. 2004; Watada et al. 2006), which is given in Eq. (2) and indicated as the dotted line in the figures. $\mathrm{PN}$ is acoustic wave and has $(w / p)_{\text {obs }}$ ranging $1-10 \mu \mathrm{m} \mathrm{s}^{-1} / \mathrm{Pa}$. The range is included in the observed values for atmosphere-to-ground signals, $0.1-10 \mu \mathrm{m} \mathrm{s}^{-1} / \mathrm{Pa}$, from various sources like volcanoes 

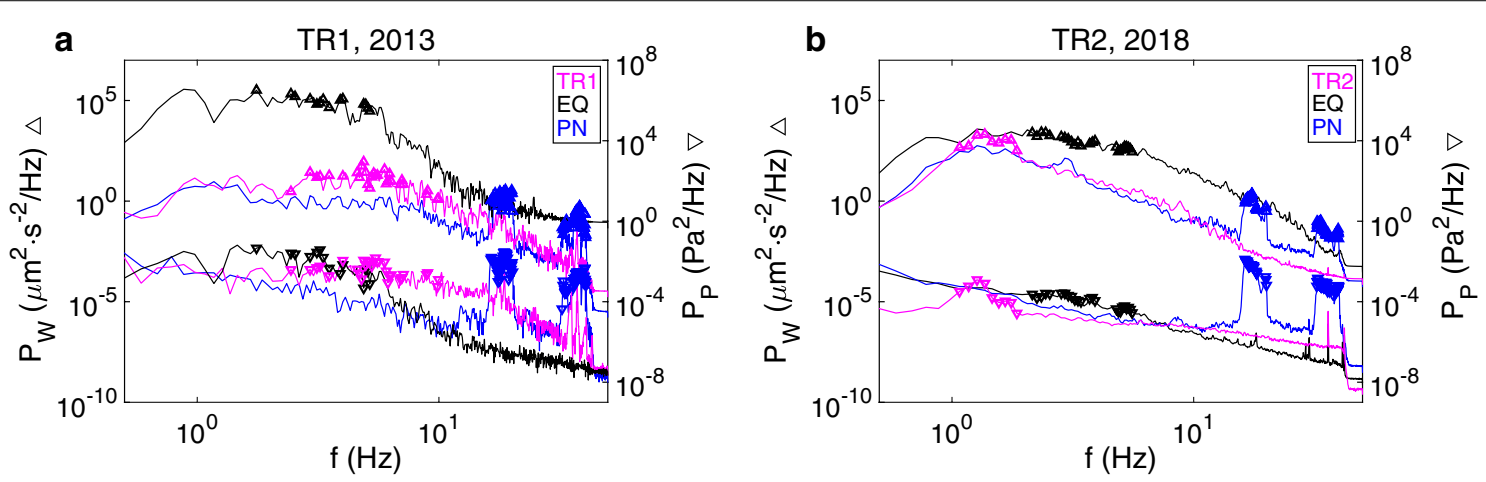

C

d
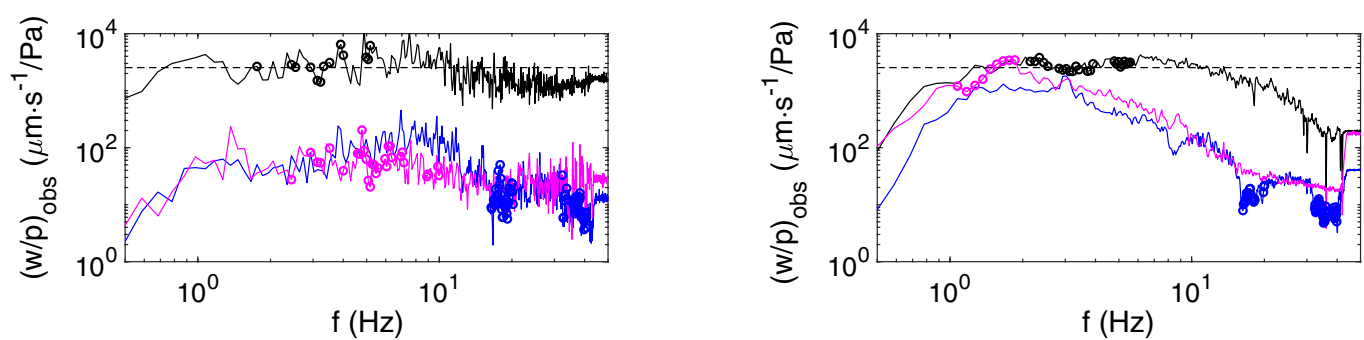

Fig. 6 The same plots of tremors (magenta) as in Fig. 3, compared with the corresponding values of EQ (black) and PN (blue)

(Nishida and Ichihara 2015; Ichihara 2016; Matoza and Fee 2014) and thunder (Lin and Langston 2007, 2009a).

We have presented Eq. (1) as the theoretical amplitude ratio for atmosphere-to-ground signals. It assumes that the atmospheric wave is propagating along the ground surface at speed much lower than the seismic waves, and the ground and the atmosphere are homogeneous halfspaces (Ben-Menahem and Singh 1981). Equation (1) with $(w / p)_{\text {obs }} \sim 10 \mu \mathrm{m} \mathrm{s}^{-1} / \mathrm{Pa}$ yields the shear modulus of $\sim 26 \mathrm{MPa}$ using $\lambda^{\prime}=\mu^{\prime}$. The shear modulus is equivalent to that of loose-packing sand or clay (Lo Presti et al. 1997), and Chidorigahara area in Ioto Island, including IOCD station, is composed almost entirely of poorly consolidated volcanic sands and gravels (Corwin and Foster 1959). However, such small moduli yield very low seismic velocities, which violate the assumption of Eq. (1). Using the general equation by Ben-Menahem and Singh (1981), the P-wave velocity in this case is estimated to be about $629 \mathrm{~m} / \mathrm{s}$ or $666 \mathrm{~m} / \mathrm{s}$, as described in Appendix A. The values are consistent with the estimated nearsurface P-wave velocity of the area, $\sim 500 \mathrm{~m} / \mathrm{s}$, which is close to the sound velocity (Kumagai and Takahashi 1985). Then, the velocities of the S-wave and the surface waves can be smaller than the sound velocity. A generic velocity structure model for volcanic areas (Lesage et al. 2018) also supports the existence of quasi-sonic or subsonic low-velocity layers within tens of meters below the surface. Besides, the incident angle of the airplane noise is not horizontal. Lin and Langston (2009a, b) analyzed seismic and infrasonic data of thunder-induced signals and showed that the ground motion is controlled by the average thickness and velocities of the near-surface layers including the topmost soft and thin layer. We avoid further interpretation of the $(w / p)_{\text {obs }}$ for infrasound because of many unknown factors. Nevertheless, it is certain that $(w / p)_{\text {obs }}$ for atmosphere-to-ground waves is much smaller than that for ground-to-atmosphere waves.

The proposed method has an advantage that it does not use the absolute values of the record. Instruments at permanent monitoring stations are not necessarily well calibrated. The field calibration of an infrasonic station is an issue. Yukutake et al. (2018) made an on-site calibration for the single microphone that recorded the 2015 Hakone eruption. They conducted the calibration after the volcanic activity declined, and found a significant deviation of the microphone response from its specification. On-site calibrations would be more difficult at isolated islands. The seismic stations can be tested using distant earthquakes recorded simultaneously by multiple stations. The same technique is not useful for infrasound, even if there is a good source and enough stations. The spatial amplitude distribution depends significantly on the atmospheric structure (Lacanna et al. 2014), which is also difficult to monitor especially at isolated islands.

\section{Volcanic activity associated with TR1 and TR2}

We found that TR1 accompanied infrasound. The infrasound might have coincided with the vent opening or the ejection of large ballistic rocks that were observed from the ground and the sky (Japan Meteorological Agency 
2013). The seismic-infrasonic cross-correlation (Fig. 4c) shows a subtle pattern change for a few minutes with TR1. In the power-spectral analysis, we selected the time windows in which the signal might dominate wind noise (step (2)). According to the span of the selected time windows, we infer that the explosive activity of the 2013 eruption lasted at least $60 \mathrm{~s}$ from 16:01 on April 11.

TR2 did not accompany apparent infrasound signals. Matsumoto et al. (2019) reported that remote hydrophones detected no relevant signal on September 12, either, even though small splashes were observed in shallow water near the Okinahama coast. Explosions under shallow water and violent water jets into the air generate detectable infrasound signals (Ichihara et al. 2009; Lyons et al. $2019,2020)$, but those were not detected in this case. If an explosion occurs in deep enough water, it may not generate infrasound (Lyons et al. 2019). However, the depth of the splashing zone near the Okinahama coast is less than $10 \mathrm{~m}$. On the other hand, gas emission into the atmosphere by a buoyant plume does not efficiently emanate infrasound (Ichihara et al. 2009). Therefore, we conclude that the unconfirmed 2018 event that generated TR2 was not an explosive eruption either on the ground or undersea.

\section{Conclusions}

We have analyzed two volcanic tremor events of Ioto Island, which were TR1 with the 2013 eruption and TR2 with the unconfirmed 2018 activity. The aim was to determine whether the events accompanied infrasound indicating the volcano's surface activity, by a single microphone that recorded the events with a co-located seismometer. With a pair of microphone and seismometer, we can sometimes detect infrasound by the seismic-infrasonic cross-correlation method. However, the method was not applicable in the studied case of Ioto Island because seismic activity was intense. Even in such a case, comparing the spectral amplitude ratios $(w / p)$ obs of the events with those of known seismic and infrasonic signals gave information.

We concluded that TR1 included infrasound, while TR2 did not. The infrasound in the part of TR1 might have been excited by the vent opening or the ejection of ballistic rocks. TR2 was not an explosive eruption either on the ground or in the shallow water. If there was any gas (and ash) emission, it might have occurred gently undersea.

Infrasonic observation is useful for the detection of eruptions. However, available infrasonic stations are limited at volcanoes on isolated volcanic islands or with less frequent eruption. Using $(w / p)$ obs with a pair of seismic and infrasonic sensors would provide a possibility of extracting infrasound signals covered by seismic signals and wind noise. Because the method refers to $(w / p)_{\text {obs }}$ of known signals, it is available without perfect calibrations for the instruments. Concerning the infrasonic reference signals, we could use various artificial and natural sources like airplane noise, bolide shockwaves, and thunder (Langston 2004; Lin and Langston 2007, 2009a).

\section{Supplementary information}

Supplementary information accompanies this paper at https://doi. org/10.1186/s40623-020-01302-2.

Additional file 1: Table S1. Timetables of EQ. 51 and 118 tectonic earth quakes that occurred in loto Island in March-April 2013 and September 2018, respectively, are selected as EQ.

\section{Abbreviations}

TR1:Tremor associated with an eruption in April 11, 2013 at loto Island; TR2: Tremor associated with an unconfirmed activity in September 12, 2018 at loto Island; PN: Referenced plane sound; EQ: Referenced tectonic earthquake; CC: Cross-correlation coefficient; $(w / p)$ obs:: Spectral amplitude ratio between seismic record and infrasonic record; PSD: Power spectral density.

\section{Acknowledgements}

The authors are grateful to the JMA, JSDF, and JVDN for providing data. We also thank Y. Masuda and Y. Kanno who supplied information on the observation condition at loto Island.

\section{Authors' contributions}

AK performed the analysis and drafted the manuscript. Ml offered technical support for the present study, and helped with discussion and revision of the manuscript. All authors read and approved the final manuscript.

\section{Funding}

A.K. was financially supported by the Japan Society for the Promotion of Science KAKENHI Grant Number JP 17K14383.

\section{Availability of data and materials}

The data set analyzed in this study is not officially available at the request of JMA and JSDF.

\section{Competing interests}

The authors declare that they have no competing interest.

\section{Author details}

${ }^{1}$ National Research Institute for Earth Science and Disaster Resilience, 3-1 Tennodai, Tsukuba, Ibaraki 305-0006, Japan. ${ }^{2}$ Earthquake Research Institute, University of Tokyo, 1-1-1 Yayoi, Bunkyo-ku, Tokyo 113-0032, Japan.

\section{Appendix A: General solution of pressure-induced surface waves}

This appendix mainly refers to Ben-Menahem and Singh (1981) for derivation of equations. Here, we assume that the ground surface is horizontal and take the $z$-axis vertical upward with $z=0$ on the surface. The sound speed in the atmosphere is $\alpha$, and P and SV wave velocities of the ground are $\alpha^{\prime}$ and $\beta^{\prime}$, respectively. A plane sound wave strikes the ground at an angle $e$ with the $z$-axis. The angles of transmission for P and SV waves in the ground are $e^{\prime}$ and $f^{\prime}$, respectively. Namely,

$$
\hat{c}=\frac{\alpha}{\sin \mathrm{e}}=\frac{\alpha^{\prime}}{\sin \mathrm{e}^{\prime}}=\frac{\beta^{\prime}}{\sin \mathrm{f}^{\prime}},
$$


where we define $\hat{c}$ as the apparent wave velocity along the surface.

Ben-Menahem and Singh (1981) represented the pressure and vertical velocity at the interface, $p^{0}$ and $w^{0}$, by the following equations:

$$
\begin{gathered}
p^{0}=p_{\text {in }} \exp \left[i \omega\left(t-\frac{x}{\hat{c}}\right)\right], \\
w^{0}=-p_{\text {in }} \frac{m_{2}}{\rho \alpha} \frac{\cos \mathrm{e}}{m_{1}} \exp \left[i \omega\left(t-\frac{x}{\hat{c}}\right)\right] \\
m_{1}=\cos \mathrm{e}\left[\left(\frac{\beta^{\prime}}{\alpha^{\prime}}\right)^{2} \sin 2 \mathrm{e}^{\prime} \sin 2 \mathrm{f}^{\prime}+\cos ^{2} 2 \mathrm{f}^{\prime}\right], \mathrm{m}_{2}=\frac{\rho \alpha}{\rho^{\prime} \alpha^{\prime}} \cos \mathrm{e}^{\prime},
\end{gathered}
$$

where $x$ is the distance along the horizontal component of the wave-incident direction, $t$ is time, $\omega$ is the angular frequency, $p_{\text {in }}$ is the amplitude of the pressure wave measured on the surface, and $\rho$ and $\rho^{\prime}$ are the densities of the air and the solid, respectively.

On the assumption that the two Lamés constants $\left(\lambda^{\prime}, \mu^{\prime}\right)$ are equal,

$$
\frac{\beta^{\prime}}{\alpha^{\prime}}=\frac{1}{\sqrt{3}}
$$

We define a dimensionless parameter:

$$
R_{p}=\frac{\alpha^{\prime}}{\alpha} \sin \mathrm{e} .
$$

Combining Eqs. (A.1)-(A.5), we obtain the dimensionless amplitude ratio,
As the shallow ground at volcanic areas generally has very low seismic velocities (Lesage et al. 2018), the above approximation is not always valid. We calculate Eq. (A.6) to obtain the efficiency of the ground motion induced by a pressure wave, $|C|$, as a function of $R_{p}$ for $\sin \mathrm{e}=1$. The result is shown in Fig. 7. In our case, pressure-induced surface waves, which are TR1 and PN, have $(w / p)_{\text {obs }} \sim 10 \mu \mathrm{m}$ $\mathrm{s}^{-1} / \mathrm{Pa}$ as shown in Fig. 6 . Therefore, $|C|$ is approximately 4.42 by normalized with $\rho^{\prime}=1.16 \mathrm{~kg} / \mathrm{m}^{3}$ and $\alpha=340$ $\mathrm{m} / \mathrm{s}$. This value is obtained with $R_{p} \sim 0.23,1.85$ and 1.96 from Fig. 7, if we assume $\sin \mathrm{e}=1$. Then, P-wave velocity becomes $78.2 \mathrm{~m} / \mathrm{s}, 629 \mathrm{~m} / \mathrm{s}$ and $666 \mathrm{~m} / \mathrm{s}$, respectively. The latter two values seem reasonable for the shallow P-wave velocity at a volcanic area (Lesage et al. 2018).

\section{Appendix B: General solution of ground-to-air wave}

Here we consider an incident seismic wave. We do not specify the type of the seismic wave, whether it is a P-wave, a $S$-wave, or a surface wave. The apparent propagation speed along the surface, $\hat{c}$, is larger than the actual seismic speed of the ground material unless the wave is propagating horizontally. In the same coordinate system as Appendix A, the vertical velocity of the ground surface at $z=0$ is assumed as

$$
w_{0}=w_{\text {in }} \exp \left[i \omega\left(t-\frac{x}{\hat{c}}\right)\right],
$$

We assume that the ground-to-air impedance contrast is infinitely large regardless of the seismic wave speed due

$$
C=\rho^{\prime} \alpha \frac{w^{0}}{p^{0}}=-\sin \mathrm{e} \frac{\sqrt{1-\mathrm{R}_{\mathrm{p}}^{2}}}{\mathrm{R}_{\mathrm{p}}}\left[\frac{4}{3 \sqrt{3}} \mathrm{R}_{\mathrm{p}}^{2} \sqrt{1-\mathrm{R}_{\mathrm{p}}^{2}} \sqrt{1-\frac{\mathrm{R}_{\mathrm{p}}^{2}}{3}}+\left(1-\frac{2}{3} \mathrm{R}_{\mathrm{p}}^{2}\right)^{2}\right]^{-1} .
$$

For most of the case, the seismic velocities of $\mathrm{P}$ and SV waves, $\alpha^{\prime}$ and $\beta^{\prime}$, respectively, are much larger than the sound speed in the air, $\alpha$. An approximate expression of Eq. (A.6) for $R_{p} \gg 1$ is given as

$$
C \sim-\frac{9}{4 R_{p}^{2}} \sin \mathrm{e} .
$$

For $\sin \mathrm{e}=1$, Eq. (A.7) gives

$$
w^{0}=\frac{3 \alpha}{4 \mu} e^{-\frac{i \pi}{2}} p_{\text {in }} \exp \left[\mathrm{i} \omega\left(\mathrm{t}-\frac{\mathrm{x}}{\alpha}\right)\right],
$$

which is equivalent with Eq. (1) of the main text for $\lambda^{\prime}=\mu^{\prime}$.

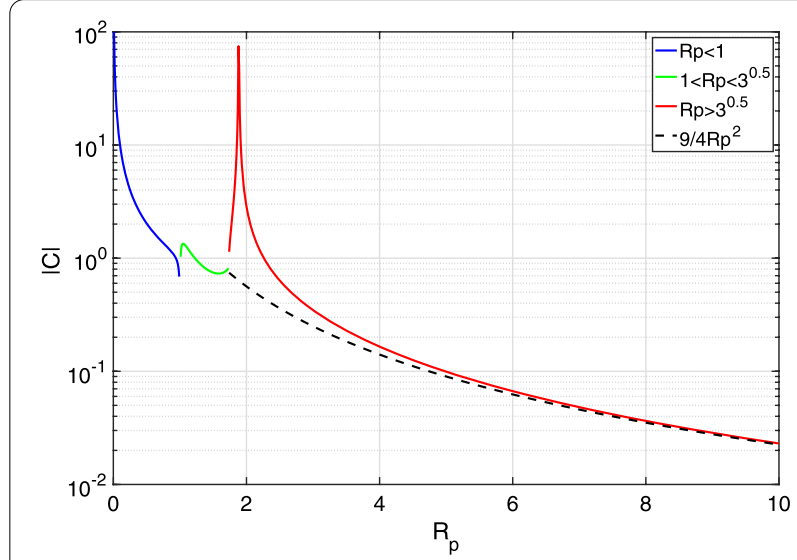

Fig. 7 The absolute value of $C$ vs. $R_{p}$ in the case of $\sin e=1$ 
to the density difference. Therefore, Eq. (B.1) is regarded as the boundary condition to the atmosphere instead of dealing with the acoustic coupling.

The wave equation in the air is obtained from the linearized basic equations

$$
\begin{aligned}
& \frac{\partial \rho}{\partial t}+\rho \nabla \cdot \mathbf{v}=0, \\
& \rho \frac{\partial \mathbf{v}}{\partial t}+\nabla \mathbf{p}=0, \\
& \frac{\Delta \rho}{\rho}=\frac{p}{K},
\end{aligned}
$$

where $\mathbf{v}$ is the velocity, $p$ is the acoustic pressure, $K \equiv \rho \alpha^{2}$ is the bulk modulus of the air, and $\Delta \rho$ is the density change corresponding to the acoustic pressure. By defining the scholar potential $\phi$, as $\mathbf{v} \equiv \nabla \phi$, Eqs. (B.2)-(B.4) are reduced to

$$
\frac{\partial^{2} \phi}{\partial t^{2}}-\alpha^{2} \nabla^{2} \phi=0 .
$$

We assume a solution of Eq. (B.5) in the form of

$$
\begin{aligned}
& \phi=\Phi \exp \left(\mathrm{i} \omega \mathrm{t}-\mathrm{ik}_{\mathrm{x}} \mathrm{x}-\mathrm{ik}_{\mathrm{z}} \mathrm{z}\right), \\
& v_{z}=-i k_{z} \Phi \exp \left(\mathrm{i} \omega \mathrm{t}-\mathrm{ik}_{\mathrm{x}} \mathrm{x}-\mathrm{ik}_{\mathrm{z}} \mathrm{z}\right),
\end{aligned}
$$

where $k_{x}$ and $k_{z}$ are the $x$ - and $z$-components of the wave number vector in the air, respectively. Using the boundary condition at $z=0$ as $v_{z}=w^{0}$, which is given in Eq. (B.1),

$$
\begin{aligned}
& k_{x}=\frac{\omega}{\hat{c}}, k_{z}=\sqrt{\frac{\omega^{2}}{\alpha^{2}}-k_{x}^{2}}=\frac{\omega}{\alpha} \sqrt{1-\frac{\alpha^{2}}{\hat{c}^{2}}}, \\
& \Phi=\frac{w_{\text {in }}}{-i k_{z}} .
\end{aligned}
$$

Substituting Eqs. (B.6) and (B.8) into Eq. (B.3),

$$
p=-\rho \frac{\partial \phi}{\partial t}=p_{w} \exp \left(\mathrm{i} \omega \mathrm{t}-\mathrm{ik}_{\mathrm{x}} \mathrm{x}-\mathrm{ik}_{\mathrm{z}} \mathrm{z}\right)
$$

where the amplitude of the pressure wave, $p_{w}$, is specified as

$$
p_{w}=\rho w_{\text {in }} \frac{\omega}{k_{z}}=\frac{\rho \alpha}{\sqrt{1-\alpha^{2} / \hat{c}^{2}}} w_{\text {in }} .
$$

When $\alpha / \hat{c} \ll 1$, Eq. (B.10) becomes $p_{w}=\rho \alpha w_{\text {in }}$, which is shown in Eq. (2) of the main text. Seismic speed of the ground at a shallow depth can be similar or even smaller than $\alpha$ in the case of this study as explained in Appendix A. However, the very low seismic velocity is expected in the depths smaller than tens of meters (Lesage et al. 2018). When the seismic velocity propagates from deeper layers, $\hat{c}$ should be larger regardless of the shallow lowvelocity layer, due to the nearly vertical angle of incidence. Therefore, the assumption of $\alpha / \hat{c} \ll 1$ is valid. Only when the seismic wave is generated in the shallow low-velocity layer, we may have $\alpha / \hat{c} \geq 1$. Such a shallow seismic source could involve the volcano's surface activity and could generate infrasound waves directly.

Received: 14 June 2020 Accepted: 22 October 2020

Published online: 09 November 2020

\section{References}

Ben-Menahem A, Singh SJ (1981) Seiemic waves and sources, 2nd edn. Dover earth science series. Springer, Berlin

Cannata A, Montalto P, Patane D (2013) Joint analysis of infrasound and seismic signals by cross wavelet transform: detection of Mt. Etna explosive activity. Nat Hazards Earth Syst Sci 13:1669-1677. https://doi.org/10.5194/ nhess-13-1669-2013

Cook RK (1971) Infrasound radiated during the Montana earthquake of 1959 August 18. Geophys J Int 26(1-4):191-198. https://doi.org/10.1111/ j.1365-246X.1971.tb03393.x

Corwin G, Foster HL (1959) The 1957 explosive eruption on Iwo jima, Volcano Islands. Am J Sci 257:161-171. https://doi.org/10.2475/ajs.257.3.161

Dempsey DE, Cronin SJ, Mei S, Kempa-Liehr AW (2020) Automatic precursor recognition and real-time forecasting of sudden explosive volcanic eruptions at Whakaari, New Zealand. Nat Commun 11:3562. https://doi. org/10.1038/s41467-020-17375-2

Donn WL, Posmentier ES (1964) Ground-coupled air waves from the Great Alaskan Earthquake. J Geophys Res 69(24):5357-5361. https://doi. org/10.1029/JZ069i024p05357

Fee D, Garces M (2007) Infrasonic tremor in the diffraction zone. Geophys Res Lett 34(16):L16826. https://doi.org/10.1029/2007GL030616

Ichihara M (2016) Seismic and infrasonic eruption tremors and their relation to magma discharge rate: A case study for sub-Plinian events in the 2011 eruption of Shinmoe-dake, Japan. J Geophys Res Solid Earth 121(10):7101-7118. https://doi.org/10.1002/2016JB013246

Ichihara M, Ripepe M, Goto A, Oshima H, Aoyama H, Iguchi M, Tanaka K, Taniguchi H (2009) Airwaves generated by an underwater explosion: implications for volcanic infrasound. J Geophys Res 114(B3):B03210. https ://doi.org/10.1029/2008JB005792

Ichihara M, Takeo M, Yokoo A, Oikawa J, Ohminato T (2012) Monitoring volcanic activity using correlation patterns between infrasound and ground motion. Geophys Res Lett 39(4):L04304. https://doi.org/10.1029/2011G L050542

Japan Meteorological Agency (2013) Monthly volcanic activity report (April 2013) (in Japanese)

Japan Meteorological Agency (2018) Monthly volcanic activity report (April 2018) (in Japanese)

Kaizuka S, Kato S, Nagaoka S, Miyauchi T (1985) Geomorphology of Iwo-jima and surrounding sea floor. J Geogr (Chigaku Zasshi) 94(6):424-436. https ://doi.org/10.5026/jgeography.94.424 (in Japanese with English abstract)

Kaneko T, Maeno F, Yasuda A, Takeo M, Takasaki K (2019) The 2017 Nishinoshima eruption: combined analysis using Himawari-8 and multiple high-resolution satellite images. Earth Planets Space 71:140. https://doi. org/10.1186/s40623-019-1121-8

Kim TS, Hayward C, Stump B (2004) Local infrasound signals from the Tokachi-Oki earthquake. Geophys Res Lett 31:L20605. https://doi. org/10.1029/2004GL021178

Kumagai T, Takahashi H (1985) Seismic wave velocity structure beneath the Iwo-jima volcanoes. J Geogr (Chigaku Zasshi) 94(6):545-550. https://doi. org/10.5026/jgeography.94.545 (in Japanese with English abstract) 
Lacanna G, Ichihara M, Iwakuni M, Takeo M, Iguchi M, Ripepe M (2014) Influence of atmospheric structure and topography on infrasonic wave propagation. J Geophys Res Solid Earth 119(4):2988-3005. https://doi. org/10.1002/2013JB010827

Langston CA (2004) Seismic ground motions from a bolide shock wave. J Geophys Res 109(B12):B12309. https://doi.org/10.1029/2004JB003167

Lesage P, Heap MJ, Kushnir A (2018) A generic model for the shallow velocity structure of volcanoes. JVolcanol Geotherm Res 356:114-126. https://doi. org/10.1016/j.jvolgeores.2018.03.003

Lin T-L, Langston CA (2007) Infrasound from thunder: a natural seismic source. Geophys Res Lett 34(14):L14304. https://doi.org/10.1029/2007GL030404

Lin T-L, Langston CA (2009a) Thunder-induced ground motions: 1. Observations. J Geophys Res 114(B4):B04303. https://doi.org/10.1029/2008JB0057 69

Lin T-L, Langston CA (2009b) Thunder-induced ground motions: 2. Site characterization. J Geophys Res 114(B4):B04304. https://doi.org/10.1029/2008J B005770

Lo Presti DCF, Jamiolkowski M, Pallara O, Cavallaro A, Pedroni S (1997) Shear modulus and damping of soils. Geotechnique 47(3):603-617. https://doi. org/10.1680/geot.1997.47.3.603

Lyons JJ, Haney MM, Fee D, Wech AG, Waythomas C (2019) Infrasound from giant bubbles during explosive submarine eruptions. Nat Geosci 12:952-958. https://doi.org/10.1038/s41561-019-0461-0

Lyons JJ, Lezzi AM, Fee D, Schwaiger HF, Wech AG, Haney MM (2020) Infrasound generated by the 2016-2017 shallow submarine eruption of Bogoslof volcano, Alaska. Bull Volcanol 82:19. https://doi.org/10.1007/ s00445-019-1355-0

Maeno F, Nakada S, Kaneko T (2016) Morphological evolution of a new volcanic islet sustained by compound lava flows. Geology 44(4):259-262. https://doi.org/10.1130/G37461.1

Mastin LG, Witter JB (2000) The hazards of eruptions through lakes and seawater. J Volcanol Geotherm Res 97:195-214. https://doi.org/10.1016/S0377 $-0273(99) 00174-2$

Matoza RS, Fee D (2014) Infrasonic component of volcano-seismic eruption tremor. Geophys Res Lett 41(6):1964-1970. https://doi. org/10.1002/2014GL059301

Matsumoto H, Zampolli M, Haralabus G, Stanley J, Mattila J, Özel NM (2019) Interpretation of detections of volcanic activity at loto Island obtained from in situ seismometers and remote hydrophones of the International Monitoring System. Sci Rep 9:19519. https://doi.org/10.1038/s4159 8-019-55918-w

McKee K, Fee D, Haney M, Matoza RS, Lyons J (2018) Infrasound signal detection and back azimuth estimation using ground-coupled airwaves on a seismo-acoustic sensor pair. J Geophys Res Solid Earth 123(8):6826-6844. https://doi.org/10.1029/2017JB015132

Nishida K, Ichihara M (2015) Real-time infrasonic monitoring of the eruption at a remote island volcano using seismoacoustic cross correlation. Geophys J Int 204:748-752. https://doi.org/10.1093/gji/ggv478

Notsu K, Sugiyama K, Hosoe M, Uemura A, Shimoike Y, Tsunomori F, Sumino H, Yamamoto J, Mori T, Hernandez PA (2005) Diffuse CO2 efflux from Iwojima volcano, Izu-Ogasawara arc, Japan. J Volcanol Geotherm Res 139:147-161. https://doi.org/10.1016/j.jvolgeores.2004.08.003

Perttu A, Caudron C, Assink JD, Metz D, Tailpied D, Perttu B, Hibert C, Nurfiani D, Pilger C, Muzli M, Fee D, Andersen OL, Taisne B (2020) Reconstruction of the 2018 tsunamigenic flank collapse and eruptive activity at Anak Krakatau based on eyewitness reports, seismo-acoustic and satellite observations. Earth Planet Sci Lett 541:116268. https://doi.org/10.1016/j. epsl.2020.116268

Ripepe M, Marchetti E, Delle Donne D, Genco R, Innocenti L, Lacanna G, Valade S (2018) Infrasonic early warning system for explosive eruptions. J Geophys Res 123(11):9570-9585. https://doi.org/10.1029/2018JB015561

Shields FD (2005) Low-frequency wind noise correlation in microphone arrays. J Acoust Soc Am 117:3489. https://doi.org/10.1121/1.1879252

Stix J, Moor JM (2018) Understanding and forecasting phreatic eruptions driven by magmatic degassing. Earth Planets Space 70:83. https://doi. org/10.1186/s40623-018-0855-z

Ueda H, Nagai M, Tanada T (2018) Phreatic eruptions and deformation of loto Island (Iwo-jima), Japan, triggered by deep magma injection. Earth Planets Space 70:38. https://doi.org/10.1186/s40623-018-0811-y

Watada S, Kunugi T, Hirata K, Sugioka H, Nishida K, Sekiguchi S, Oikawa J, Tsuji Y, Kanamori H (2006) Atmospheric pressure change associated with the 2003 Tokachi-Oki earthquake. Geophys Res Lett 33(24):L24306. https:// doi.org/10.1029/2006GL027967

Williams R, Rowley P, Garthwaite MC (2019) Reconstructing the Anak Krakatau flank collapse that caused the December 2018 Indonesian tsunami. Geology 47(10):973-976. https://doi.org/10.1130/G46517.1

Yukutake Y, Ichihara M, Honda R (2018) Infrasonic wave accompanying a crack opening during the 2015 Hakone eruption. Earth Planets Space 70:53. https://doi.org/10.1186/s40623-018-0820-x

\section{Publisher's Note}

Springer Nature remains neutral with regard to jurisdictional claims in published maps and institutional affiliations.

\section{Submit your manuscript to a SpringerOpen ${ }^{\circ}$ journal and benefit from:}

- Convenient online submission

- Rigorous peer review

- Open access: articles freely available online

- High visibility within the field

- Retaining the copyright to your article

Submit your next manuscript at $\boldsymbol{\nabla}$ springeropen.com 